\title{
Effects of Glucose Control and Variability on Endothelial Function and Repair in Adolescents with Type 1 Diabetes
}

\author{
Robert P. Hoffman, ${ }^{1}$ Amanda S. Dye, ${ }^{2}$ Hong Huang, ${ }^{3}$ and John A. Bauer ${ }^{1}$ \\ ${ }^{1}$ Department of Pediatrics, The Ohio State University, The Research Institute at Nationwide Children's Hospital, 700 Children's Drive, \\ ED422, Columbus, OH 43205, USA \\ ${ }^{2}$ Department of Pediatrics, West Virginia University, 830 Pennsylvania Avenue Suite 104, Charleston, WV 25302, USA \\ ${ }^{3}$ Research Institute at Nationwide Children's Hospital, 700 Children's Drive, Columbus, OH 43205, USA
}

Correspondence should be addressed to Robert P. Hoffman; robert.hoffman@nationwidechildrens.org

Received 11 September 2013; Accepted 8 October 2013

Academic Editors: G. Chiari, O. Giampietro, and M. Prazny

Copyright (C) 2013 Robert P. Hoffman et al. This is an open access article distributed under the Creative Commons Attribution License, which permits unrestricted use, distribution, and reproduction in any medium, provided the original work is properly cited.

\begin{abstract}
Background. Endothelial dysfunction and increased inflammation are precursors of cardiovascular disease in type 1 diabetes (T1D) and occur even in adolescents with T1D. The goal of this study was to determine the relationship of endothelial dysfunction to various measures of glycemia. Research Design and Methods. Forearm blood flow (FBF, venous occlusion plethysmography) was measured before and after $5 \mathrm{~min}$ of upper arm vascular occlusion in 17 adolescents with uncomplicated type 1 diabetes. Endothelial function was assessed as postocclusion FBF and forearm vascular resistance (FVR, mean arterial pressure/FBF). Fasting glucose, 72 hour mean glucose and standard deviation from continuous glucose monitoring, hemoglobin Alc, and hemoglobin Alc by duration area under the curve were used to assess immediate, short-term, and intermediate- and long-term glycemia. Results. Postocclusion FBF $(r=-0.53, P=0.030)$ negatively correlated and postocclusion FVR positively correlated $(r=0.52, P=0.031)$ with hemoglobin Alc levels. FVR was positively associated with $\log 3$ day mean glucose $(r=0.55, P=0.027)$. Postocclusion FBF $(2.8 \pm 1.1$ versus $3.4 \pm 0.5 \mathrm{~mL} / \mathrm{dL} / \mathrm{min}$, mean $\pm \mathrm{SE}, P=0.084)$ tended to be lower and FVR $(31.4 \pm 10.4$ versus $23.9 \pm 4.4 \mathrm{mmHg} \mathrm{dL} \mathrm{min} / \mathrm{mL}$, $P=0.015)$ was significantly higher in subjects with hemoglobin Alc above the median (8.3\%) compared to those with lower hemoglobin Alc levels. Conclusions. These results demonstrate that poor intermediate-term glycemic control is associated with impaired endothelial function.
\end{abstract}

\section{Background}

Vascular endothelial dysfunction contributes to the development of both macrovascular and microvascular complications in type 1 diabetes (T1D) and there is considerable evidence that patients with T1D have increased endothelial stress/injury and reduced endothelial repair. Recent studies have indicated that adolescents with T1D have impaired flow mediated vasodilation, as measured using either brachial artery ultrasound or venous occlusion plethysmography [16]. Flow mediated vasodilation is due to endothelial nitric oxide release and thus is an effective measure of endothelial function.

Beyond this, there is good evidence of impaired endothelial repair capacity in T1D. Studies in mice indicate that animals with streptozotocin-induced diabetes have impaired vascular repair following hindlimb ischemia [7]. Similarly, vascular repair is impaired in control animals following transplantation of bone marrow derived stem cells from diabetic animals compared to those receiving cells from healthy animals [8]. Both studies indicated that progenitor cell counts were reduced in diabetic animals. Studies in humans have generally indicated reduced progenitors cell counts in young adults with T1D without overt complications [9-11]. Interestingly, in T1D adolescents, Dimeglio et al. [12] found decreased CD $34+\mathrm{CD} 133+\mathrm{CD} 31+$ or circulating endothelial progenitor cells (CPCs), as reported in adults, but increased CD34+ CD45- cells or endothelial colony forming cells (ECFCs). They also found a negative relationship between the ECFCs and CPCs. They believed that 
the decreased CPCs indicated reduced repair capacity and the increased ECFCs were due to increased recruitment due to ongoing endothelial damage. The former conclusion was confirmed by a positive relationship between CPCs and endothelial function as measured using skin blood flow response to acetylcholine iontophoresis. Importantly, they found no relationships between any measure of glucose control and either CPCs or ECFCs.

Hyperglycemia-induced oxidative stress plays a key pathophysiological role in damaging endothelial function in diabetes $[13,14]$. Acute hyperglycemia, also, profoundly increases muscle blood flow probably through osmotic effects in both healthy adults [15] and adolescents with T1D [16]. This pronounced increase in blood flow leads to a diminished incremental response to flow mediated vasodilation, possibly through a ceiling effect. A direct adverse effect of glucose variability on endothelial cells has, also, been demonstrated. Protein kinase-c levels, apoptotic rates, and biochemical markers of endothelial cell dysfunction are higher in endothelial cells exposed to intermittent glycemic levels of 90 or $360 \mathrm{mg} / \mathrm{dL}$ than in cells exposed continuously to either 90 or $360 \mathrm{mg} / \mathrm{dL}$ [17]. It is thought that the glucose fluctuations prevent the cells from adapting to the hyperglycemic condition. The adverse effect of oscillating glucose levels has been confirmed in adults with and without type 2 diabetes. Oscillating hyperglycemic and euglycemic clamp over 24 hours leads to greater impairment in endothelial function (measured using flow mediated vasodilation) and greater oxidative damage via reactive nitrogen species than does constant hyperglycemia [18].

Because of the above data, the primary goals of this study were to determine the effects of various measures of glycemia on endothelial function and endothelial repair capacity in adolescents with T1D. Specific measures that were studied include fasting glucose, 3 day average glucose and glucose standard deviation as determined via continuous glucose monitoring, hemoglobin Alc, and hemoglobin Alc area under the curve since diagnosis of diabetes (HbAlcAUC). Increasing our understanding how glucose control affects endothelial function and repair in adolescents will enhance our knowledge of the early pathophysiology of cardiovascular disease in T1D.

\section{Methods}

2.1. Subjects. 17 adolescents (8 females, 9 males) with type $1 \mathrm{DM}$ were recruited from the Pediatric Diabetes Clinic of Nationwide Children's Hospital ( $\mathrm{NCH})$. Their mean age was $13.1 \pm 1.6$ years (mean $\pm \mathrm{SD}$ ) and their mean body mass index was $20.3 \pm 3.1 \mathrm{~kg} / \mathrm{m}^{2}$. Mean HgbAlc was $8.3 \pm 1.2 \%$ and mean duration of diabetes was $4.8 \pm 3.8$ years. The study was approved by the NCH Institutional Review Board and informed consent was obtained from parent or legal guardian. Proper assent was obtained from all subjects.

Screening included a history, physical exam, Tanner staging, and fasting laboratory testing. Type $1 \mathrm{DM}$ was defined by the American Diabetes Association Criteria plus a fasting C-peptide of less than $0.4 \mathrm{ng} / \mathrm{mL}$, insulin monotherapy since diagnosis, and an absence of a history of oral hypoglycemic agents and acanthosis nigricans on exam. All subjects were nonsmokers by report.

All subjects were Tanner stage 2-4 in order to minimize the effects of starting or finishing puberty. In order to limit confounding effects on endothelial function, subjects with BP > 95\% tile, smoking, pregnancy, and uncorrected hypothyroidism were excluded. Subjects with microalbuminuria, overt nephropathy, or early renal failure (random urine microalbumin/creatinine $>0.02 \mathrm{mg}$ albumin $/ \mathrm{mg}$ creatinine; serum creatinine $>1.0 \mathrm{mg} / \mathrm{dL}$ ) were also excluded.

2.2. Protocol. Subjects were admitted to the Clinical Research Center of the Wexner Medical Center at the Ohio State University at 0730 after having fasted from 2200 the night before. Subjects were instructed to take their usual basal insulin the night before or to remain on their usual basal insulin infusion rates if using continuous subcutaneous insulin. Subjects withheld their morning insulin bolus until breakfast was given after the study completion. Endothelial testing was then conducted as described below. A 20-minute rest period was held before endothelial-independent vasodilation assessed using sublingual $0.3 \mathrm{mg}$ of glycerol trinitrate. A blood sample was then collected for measurement of fasting glucose and ECFCs. Eleven patients then participated in an insulin clamp study to assess the effects of glucose normalization and hyperglycemia. Results on this study have been previously reported [16]. Subjects were then placed on a continuous 24hour glucose monitor (Medtronic Guardian, Fridley MN) for 3 days after which the monitor was returned and the data was downloaded using the Medtronic Carelink website to determine the mean glucose level and standard deviation.

\subsection{Assessment of Endothelial and Nonendothelial Vasodila-} tion. Forearm Blood Flow (FBF) was measured using strain gauge venous occlusion plethysmography, as previously described by Higashi and Yoshizumi [19], using a Hokanson EC6 plethysmograph (DE Hokanson Inc, Bellevue, WA) in the dominant arm. An indium-in-silastic strain gauge was attached to the widest portion of the forearm and connected to a plethysmography device. Sphygomanometric cuffs were placed on the arm at the wrist and on the upper arm. The wrist cuff was inflated to $200 \mathrm{mmHg}$ to occlude blood flow to the hand for the duration of the study. During FBF measurement the upper arm cuff was inflated to $40 \mathrm{mmHg}$ for 10 out of 15 seconds to occlude venous return but not arterial inflow. Each subject had two minutes of baseline flow recorded and then the upper arm cuff was inflated to $200 \mathrm{mmHg}$ pressure for five minutes to occlude arterial flow to the arm. It was then released to create a sudden shear stress. FBF was again measured for the next minute. The FBF outflow signal was transmitted to a recorder (Powerlab 8, ADInstruments, Colorado Springs, CO) and FBF was expressed as $\mathrm{mL}$ per minute per $100 \mathrm{~mL}$ of forearm tissue volume. Forearm vascular resistance (FVR) was calculated by dividing mean arterial pressure (measured by automated sphygmomanometer) by FBF. All studies were scored by a single experienced investigator (RPH).

FBF was measured for 1 minute before and 5 minutes after glycerol trinitrate. The highest percent increase in $1 \mathrm{~min}$ 


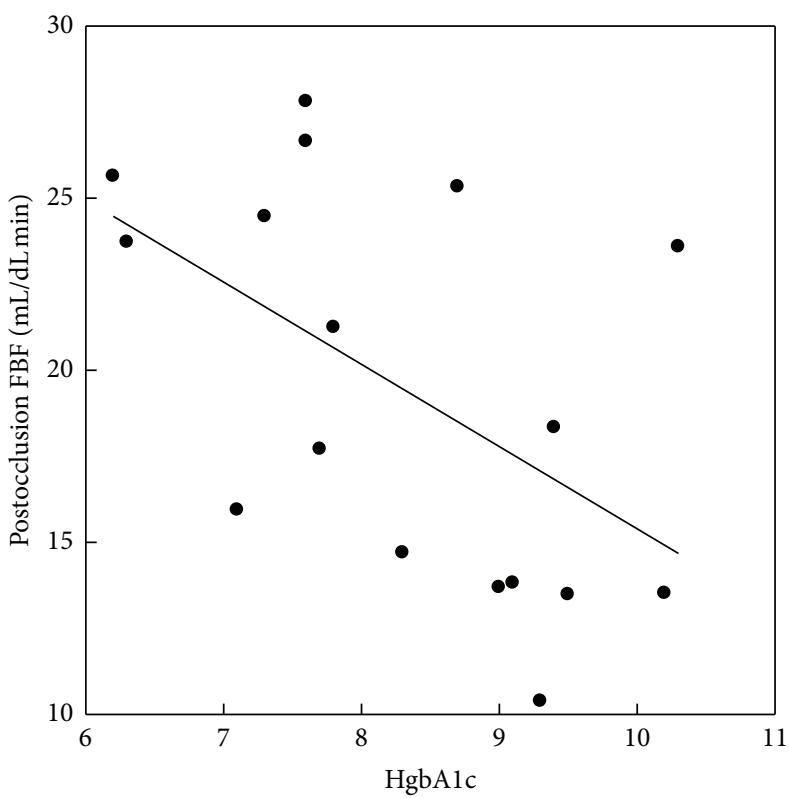

(a)

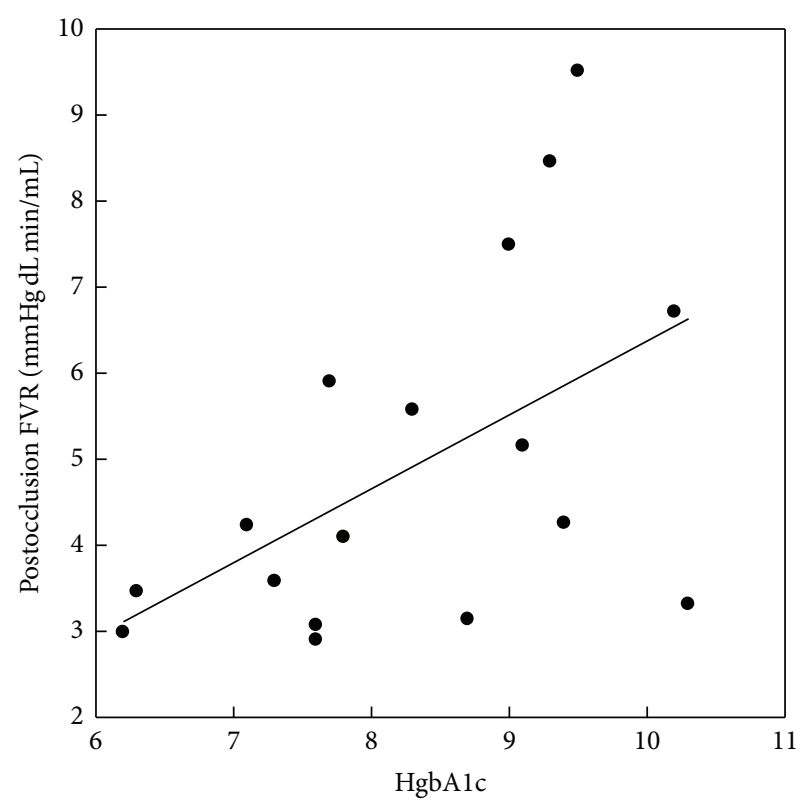

(b)

FIGURE 1: Relationships of postocclusion forearm blood flow $(r=-0.53, P=0.030)$ and vascular resistance to hemoglobin Alc in adolescents with type 1 diabetes $(r=0.52, P=0.031)$.

postnitrate FBF or largest percent fall in FVR were used to assess endothelial-independent vasodilation.

2.4. Laboratory Measurements. Hemoglobin Alc levels were taken from the Pediatric Diabetes Clinic at Nationwide Children's. Measurements in the clinic are done using point of care testing on the DCA 2000 (Leverkusen, Germany).

ECFCs were measured using polychromatic flow cytometry methods. A $50 \mu \mathrm{L}$ volume anticoagulated peripheral blood was incubated with $50 \mu \mathrm{L} \mathrm{3 \%} \mathrm{BSA} \mathrm{in} \mathrm{PBS} \mathrm{(without}$ $\mathrm{Ca}++$ and $\mathrm{Mg}++$ ) at room temperature for $30 \mathrm{~min}$. In dark, fluorescence labeled antibodies $(2.5 \mu \mathrm{L}$ of each), PE-AC133, FITC-CD34, and PECy5-CD45, were added and incubated for $30 \mathrm{~min}$ at room temperature. FACS lysis buffer $(450 \mu \mathrm{L})$ was then added and incubated for $30 \mathrm{~min}$ at room temperature in dark. Samples were then analyzed on a FACS Calibur flow cytometer, where total counts are $>400,000$ cells. Intraassay variability from $\sim 100 \mu \mathrm{L}$ whole blood was $<5 \%$.

2.5. Statistical Analysis. HbAlcAUC was calculated using the trapezoidal rule. Pearson regression analysis was used to assess the relationship between vascular, ECFC's, and inflammatory and oxidative markers and the various measures of glucose control. $t$-tests were used for group comparisons. Data was log normalized, as needed. Analysis was performed using Systat 11 (SAS, Systat Software Inc, Chicago, IL). Results are shown as mean $\pm \mathrm{SD}$.

\section{Results}

3.1. Vascular Measures. Mean postocclusion FBF for the group was 19.2 $\pm 5.7 \mathrm{~mL} / \mathrm{dL}$ min. Postocclusion FBF decreased as age increased $(r=-0.55, P=0.023)$ and as glucose control worsened as indicated by a negative relationship with the hemoglobin Alc at the time of study $(r=-0.53, P=$ 0.030 , Figure 1). The diminished postocclusive FBF was due to impaired vasodilation since postocclusive FVR increased as single hemoglobin Alc increased ( $r=0.52, P=0.031)$. Postocclusive FBF was not related to fasting glucose, 3 day mean glucose, or HbAlcAUC.

Mean postocclusive FVR was $4.9 \pm 2.0 \mathrm{mmHg} \mathrm{dL} \mathrm{min} / \mathrm{mL}$. Postocclusive FVR was positively related to $\log 3$ day mean glucose $(r=0.55, P=0.027$ Figure 2$)$ and tended to be positively related to fasting glucose $(r=0.44, P=0.098)$ but not to glucose standard deviation. Stepwise multiple regression including hemoglobin Alc, fasting, and $\log 3$ day mean glucose revealed that only the $\log 3$ day mean glucose significantly predicted postocclusion FVR. The ratio of post to preocclusive FBF was not related to any measure of glucose control while the percent change in FVR from preocclusion to postocclusion tended to worsen as fasting glucose increased $(r=0.46, P=0.088)$.

Postocclusive FBF decreased as age increased $(r=-0.55$, $P=0.023$ ) but was not related to BMI. None of the postocclusive FVR measures were significantly related to age or BMI. Neither postocclusive FBF nor postocclusive FVR was related to endothelial-independent vasodilation. Log absolute ECFC and percent ECFC were not significantly related to any glycemic measures, age, or BMI.

Median hemoglobin A1c for the 17 T1D subjects was $8.3 \%$. To confirm the relationships of endothelial function to glycemic control, subjects were divided into two groups with hemoglobin Alc levels above and below the median. Table 1 shows age, duration of diabetes, BMI, blood pressure, and pre- and postocclusion FBF and FVR values for the 


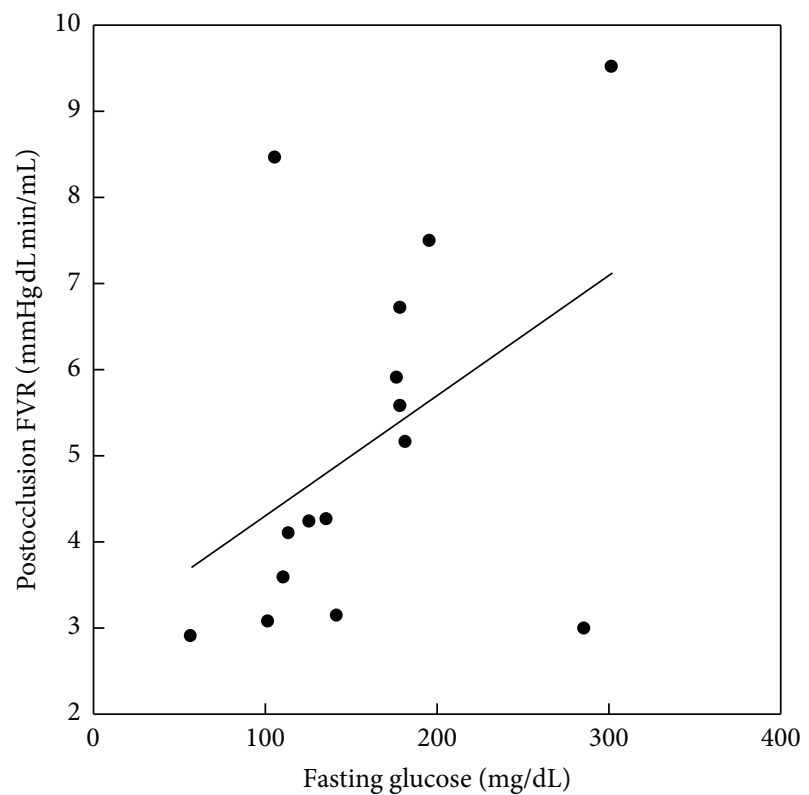

(a)

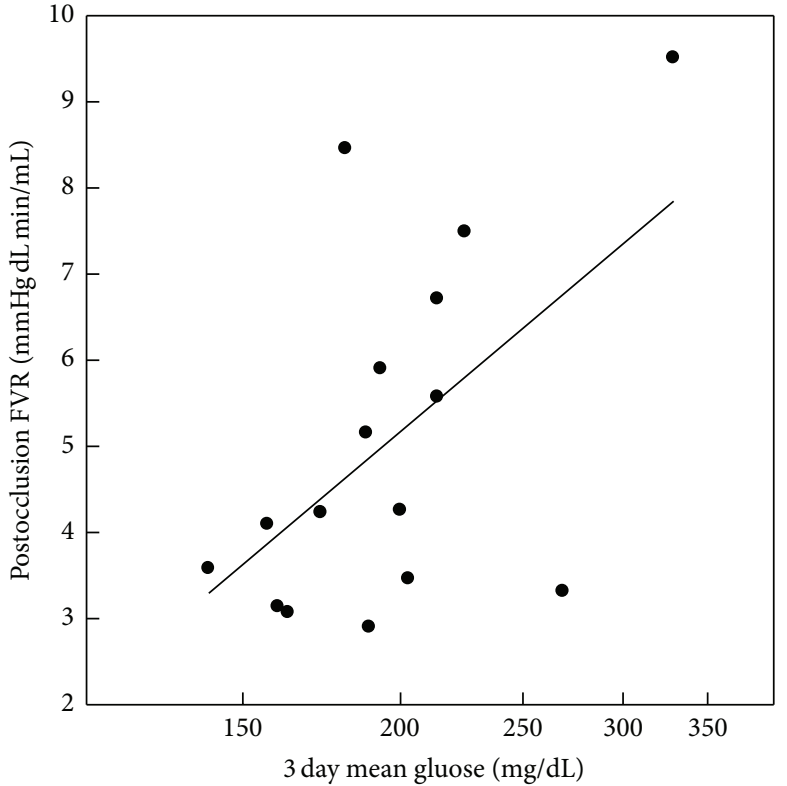

(b)

FIGURE 2: Relationships of postocclusion forearm vascular resistance to fasting glucose $(r=0.44, P=0.098)$ and 72 hour mean glucose $(r=0.55, P=0.027)$ in adolescents with type 1 diabetes.

TABLE 1: Demographics, blood pressure, and pre-and postocclusion FBF and FVR in adolescents with type 1 diabetes according to glucose control.

\begin{tabular}{lcc}
\hline & Alc $\leq 8.3 \%$ & Alc $>8.3 \%$ \\
\hline Age (years) & $12.5 \pm 1.6$ & $13.8 \pm 1.2$ \\
Duration (years) & $4.1 \pm 2.5$ & $5.4 \pm 5.1$ \\
BMI (kg/m $\left.{ }^{2}\right)$ & $20.1 \pm 4.0$ & $20.4 \pm 2.0$ \\
SBP $(\mathrm{mmHg})$ & $106 \pm 5$ & $107 \pm 7$ \\
DBP $(\mathrm{mmHg})$ & $63 \pm 10$ & $60 \pm 8$ \\
\hline & \multicolumn{2}{c}{ Preocclusion } \\
FBF (mL/dL min) & $3.4 \pm 0.5$ & $2.8 \pm 1.1$ \\
FVR (mmHg dL min/mL) & $23.9 \pm 4.4$ & $31.4 \pm 10.4^{\mathrm{b}}$ \\
\hline & \multicolumn{2}{c}{ Postocclusion } \\
FBF (mL/dL min) & $22.0 \pm 4.8$ & $16.5 \pm 5.3^{\mathrm{a}}$ \\
FVR (mmHg dL min $/ \mathrm{mL})$ & $4.0 \pm 1.1$ & $6.0 \pm 2.3^{\mathrm{c}}$ \\
\hline
\end{tabular}

${ }^{\mathrm{a}} P=0.084$ versus well-controlled, ${ }^{\mathrm{b}} P=0.047$ versus well-controlled, and

${ }^{\mathrm{c}} P=0.015$ versus well-controlled.

two groups. Age, duration of diabetes, BMI, and blood pressure did not differ between the two groups. Both pre- and postocclusion FVR were increased in subjects with poorly controlled compared to well-controlled T1D. The results were confirmed by the FBF results where postocclusion FBF tended to be lower in poorly controlled T1D compared to well-controlled T1D $(P=0.084)$. ECFC's and maximal vasodilation in response to sublingual nitroglycerin T1D did not differ between poorly and well-controlled T1D subjects.

\section{Discussion}

The results clearly demonstrate that in adolescent TiD poor intermediate-term glucose control impairs endothelial function since postocclusive FBF decreased and postocclusive FVR increased as hemoglobin Alc increased, indicating impaired maximal sheer stress and nitric oxide-induced vasodilation. This was confirmed by the increased postocclusive FVR and trend toward decreased FBF in poorly controlled TiD compared to well-controlled subjects.

Multiple methods have been used to assess endothelial function in the normal population and in adolescents with T1D [1-6]. These methods generally assess the change in either brachial artery diameter as indicated by ultrasound or the change in FBF or FVR as measured by venous occlusion plethysmography following upper arm vascular occlusion. While it is clear that this reactive hyperemic response is mediated by endothelial nitric oxide release [19], it is less clear which method is best to assess endothelial function in T1D. Furthermore, data from our laboratory indicates that acute hyperglycemia markedly increases preocclusion FBF and decreases preocclusion FVR which creates a ceiling and a floor effect, respectively, for assessing postocclusion changes in FBF and FVR [16]. Studies of young adult patients with T1D have demonstrated decreased basal limb blood flow in the leg [20] while studies in long standing T1D without complications have demonstrated increased limb blood flow in the arm [21]. Babar et al. found larger brachial artery baseline diameters in prepubertal subjects with T1D compared to control subjects [6]. From this data, it is clear that different plasma glucose levels may lead to alterations in basal (preocclusion) blood flow and brachial artery diameter that may potentially alter change measurements in FBF or brachial artery diameter, as indicators of endothelial function.

Recently, Nadeau et al. [4] have simply reported decreased postocclusive FBF in adolescents with T1D without assessing 
change scores. The diminished postocclusive FBF is likely an indicator of impaired, maximal endothelially induced vasodilation in adolescents with T1D. The data in the current study expand this finding by indicating that maximal postocclusive vasodilation decreases as intermediate- and short-term glucose control worsen as indicated by lower FBF and higher FVR with increasing hemoglobin Alc. The short-term nature of this effect was demonstrated by the fact that postocclusive FVR increased as 3 day average glucose increased. This decreased ability to increase blood flow in response to shear stress with poor glucose control may play a significant role in the development of cardiovascular disease in T1D. Endothelial dysfunction is, also, thought to play a significant role in the diabetic microvascular complications as well $[13,14,22,23]$.

In our study, intermediate-term and short-term glucose control (single hemoglobin Alc and 3 day mean glucose) were clearly associated with impaired endothelial function. This is the opposite of the findings of Babar et al. who found better endothelial function in T1D prepubertal subjects with poor glucose control [6]. They had no explanation for this finding. In older adolescents with less than 5 years duration, Ce et al. found that brachial artery flow mediated dilation significantly negatively correlated with mean hemoglobin Alc levels between 12 and 24 months before the measurement but not mean hemoglobin Alc levels between 0 and 12 months before the measurement [24]. They did not find this relationship in subjects with more than 5 years duration. They suggested that this relationship was an evidence of a metabolic memory affect. Our data is somewhat different in that we found a direct relationship with current hemoglobin Alc and no relationship to long-term glycemic control as indicated by HbAlcAUC. When only patients under 5 years duration were studied the relationships between FBF and single hemoglobin Alc and between FVR and $\log 3$ day mean glucose remained significant (data not shown). Too few subjects had duration of more than 5 years to adequately assess whether there were duration related differences in these relationships but multilinear regression analysis did not reveal significant duration by hemoglobin Alc interactions. The reason that recent hemoglobin Alc had an effect in our study, and not theirs, is not immediately apparent. Possible explanations would include the younger subjects in the current study and different methods of assessing endothelial function. The importance of the effect of poor glycemic control is emphasized when postocclusion FBF and FVR from the T1D subjects are compared to that of results from healthy, pubertal control subjects from a previous study (FBF: $22.5 \pm 4.5 \mathrm{~mL} / \mathrm{dL}$ min; FVR: $4.1 \pm 1.5 \mathrm{mmHg} \mathrm{dL} \mathrm{min} / \mathrm{mL}$ ) [25]. Postocclusion FBF was significantly lower and FVR significantly increased in the subjects with hemoglobin Alc above the median.

Glucose variability was not significantly related to either postocclusive FBF or FVR. This finding was somewhat surprising since in vitro [17] and in vivo [18] studies have indicated that oscillating glucose leads to impaired endothelial function. These results, however, confirm results from Pena et al. which found no relationship between endothelial function, measured using brachial artery, flow-mediated vasodilation, and glucose variability from the continuous glucose monitor [5]. Interestingly, they did find a negative effect of hypoglycemia on endothelial function. We did not assess this relationship. Long-term glucose control was not significantly related to measures of endothelial function.

We found no relationships between ECFC's and glucose control. ECFC\% was increased in our subjects compared to age-matched control subjects from a previous study (T1D, $0.115 \pm 0.074$ versus controls, $0.022 \pm 0.017 \%$, mean \pm SD, $P=0.016)$ confirming previous findings by Dimeglio et al. [12]. They believed that the increased ECFCs in T1D were due to an ongoing response to endothelial injury; thus, it would be expected that ECFC counts would increase as endothelial function deteriorates. However, neither Dimeglio et al. nor we found a significant relationship between ECFCs and endothelial function [12]. They did find a negative relationship between CPCs, which we did not assess, and endothelial function. Hortenhuber et al. [26] found no difference in what they called circulating progenitor cells $(C D$ $34+\mathrm{CD} 133+$ ) between control and type 1 diabetic subjects and lower endothelial progenitor cells (CD34+ CD133+ CD309+) in type 1 diabetes adolescents. They also found that these latter cells decreased as hemoglobin Alc increased.

The main limitation of this study is the small number of subjects studied which decreases our ability to truly assess the interactions between immediate, short-term, intermediateterm, and long-term glucose control and endothelial function. This was particularly true regarding postocclusive FVR which was significantly related to $\log 3$ day mean glucose and single hemoglobin Alc and tended to be related to fasting glucose since log average glucose was positively correlated with both hemoglobin Alc $(r=0.56, P=0.025)$ and fasting glucose $(r=0.88, P<0.001)$ while the latter two were not related. The fact that postocclusive FBF was only related to single hemoglobin Alc supports our contention that intermediate glycemic control is most important.

\section{Conclusions}

Our results demonstrate that short and intermediate-term, poor glucose control are associated with diminished endothelial function in pubertal T1D adolescents. Since impaired endothelial function is a precursor for future cardiovascular disease, these results emphasize the need to achieve good diabetes control in adolescents.

\section{Abbreviations \\ BMI: $\quad$ Body mass index \\ CPCs: $\quad$ Circulating progenitor cells \\ ECFCs: Endothelial colony forming cells \\ FBF: $\quad$ Forearm blood flow \\ FVR: $\quad$ Forearm vascular resistance \\ HbAlcAUC: Area under curve of hemoglobin Alc by duration curve \\ T1D: $\quad$ Type 1 diabetes.}

\section{Conflict of Interests}

The authors have no conflict of interests related to this paper. 


\section{Author's Contributions}

Robert P. Hoffman wrote protocol and obtained research funding, supervised or directly collected data, and wrote and edited the paper. $\mathrm{He}$ is responsible for its content. Amanda S. Dye participated in data collection and reviewed the manuscript. Hong Huang performed laboratory measurement and reviewed the paper. John A. Bauer supervised laboratory measurements and reviewed and edited manuscript. Dr. Robert Hoffman is the guarantor of this work and, as such, had full access to all the data in the study and takes responsibility for the integrity of the data and the accuracy of the data analysis.

\section{Acknowledgments}

The authors thank Karen Carter, Lauren Bird, and Jesse Haines (Research Institute at Nationwide Children's Hospital) for their help with recruiting subjects and performing the research and the nurses of the CRC for their help with the blood drawing. This study was supported by the National Institutes of Health NIDDK Grant no. R21DK083642-01 and the American Reinvestment and Recovery Act of 2009. The project described was, also, supported by the Award no. UL1RR025755 from the National Center for Research Resources. The content is solely the responsibility of the authors and does not necessarily represent the official views of the National Center for Research Resources or the National Institutes of Health.

\section{References}

[1] K. C. Donaghue, J. Robinson, R. McCredie, A. Fung, M. Silink, and D. S. Celermajer, "Large vessel dysfunction in diabetic adolescents and its relationship to small vessel complications," Journal of Pediatric Endocrinology and Metabolism, vol. 10, no. 6, pp. 593-598, 1997.

[2] M. J. Järvisalo, M. Raitakari, J. O. Toikka et al., "Endothelial dysfunction and increased arterial intima-media thickness in children with type 1 diabetes," Circulation, vol. 109, no. 14, pp. 1750-1755, 2004.

[3] E. J. Wiltshire, R. Gent, C. Hirte, A. Pena, D. W. Thomas, and J. J. Couper, "Endothelial dysfunction relates to folate status in children and adolescents with type 1 diabetes," Diabetes, vol. 51, no. 7, pp. 2282-2286, 2002.

[4] K. J. Nadeau, J. G. Regensteiner, T. A. Bauer et al., "Insulin resistance in adolescents with type 1 diabetes and its relationship to cardiovascular function," Journal of Clinical Endocrinology and Metabolism, vol. 95, no. 2, pp. 513-521, 2010.

[5] A. S. Pena, J. J. Couper, J. Harrington et al., "Hypoglycemia, but not glucose variability, relates to vascular function in children with type 1 diabetes," Diabetes Technology \& Therapeutics, vol. 14, no. 6, pp. 457-462, 2012.

[6] G. S. Babar, H. Zidan, M. E. Widlansky et al., "Impaired endothelial function in preadolescent children with type 1 diabetes," Diabetes Care, vol. 34, no. 3, pp. 681-685, 2011.

[7] J. Yan, G. Tie, B. Park, Y. Yan, P. T. Nowicki, and L. M. Messina, "Recovery from hind limb ischemia is less effective in type 2 than in type 1 diabetic mice: roles of endothelial nitric oxide synthase and endothelial progenitor cells," Journal of Vascular Surgery, vol. 50, no. 6, pp. 1412-1422, 2009.

[8] A. Orlandi, E. Chavakis, F. Seeger, M. Tjwa, A. M. Zeiher, and S. Dimmeler, "Long-term diabetes impairs repopulation of hematopoietic progenitor cells and dysregulates the cytokine expression in the bone marrow microenvironment in mice," Basic Research in Cardiology, vol. 105, no. 6, pp. 703-712, 2010.

[9] N. Kränkel, S. P. Armstrong, C. A. McArdle, C. Dayan, and P. Madeddu, "Distinct kinin-induced functions are altered in circulating cells of young type 1 diabetic patients," PloS One, vol. 5, no. 6, p. el1146, 2010.

[10] L. Sibal, A. Aldibbiat, S. C. Agarwal et al., "Circulating endothelial progenitor cells, endothelial function, carotid intima-media thickness and circulating markers of endothelial dysfunction in people with type 1 diabetes without macrovascular disease or microalbuminuria," Diabetologia, vol. 52, no. 8, pp. 1464-1473, 2009.

[11] O. van Oostrom, D. P. V. de Kleijn, J. O. Fledderus et al., "Folic acid supplementation normalizes the endothelial progenitor cell transcriptome of patients with type 1 diabetes: a case-control pilot study," Cardiovascular Diabetology, vol. 8, article 47, 2009.

[12] L. A. Dimeglio, A. Tosh, C. Saha et al., "Endothelial abnormalities in adolescents with type 1 diabetes: a biomarker for vascular sequelae?" Journal of Pediatrics, vol. 157, no. 4, pp. 540-546, 2010.

[13] H. Cai and D. G. Harrison, "Endothelial dysfunction in cardiovascular diseases: the role of oxidant stress," Circulation Research, vol. 87, no. 10, pp. 840-844, 2000.

[14] C. D. A. Stehouwer, J. Lambert, A. J. M. Donker, and V. W. M. van Hinsbergh, "Endothelial dysfunction and pathogenesis of diabetic angiopathy," Cardiovascular Research, vol. 34, no. 1, pp. 55-68, 1997.

[15] R. P. Hoffman, M. Hausberg, C. A. Sinkey, and E. A. Anderson, "Hyperglycemia without hyperinsulinemia produces both sympathetic neural activation and vasodilation in normal humans," Journal of Diabetes and its Complications, vol. 13, no. 1, pp. 17-22, 1999.

[16] A. S. Dye, H. Huang, J. A. Bauer, and R. P. Hoffman, "Hyperglycemia increases muscle blood flow and alters endothelial function in adolescents with type 1 diabetes," Experimental Diabetes Research, vol. 2012, Article ID 170380, 9 pages, 2012.

[17] I. B. Hirsch and M. Brownlee, "Should minimal blood glucose variability become the gold standard of glycemic control?" Journal of Diabetes and its Complications, vol. 19, no. 3, pp. 178181, 2005.

[18] A. Ceriello, K. Esposito, L. Piconi et al., "Oscillating glucose is more deleterious to endothelial function and oxidative stress than mean glucose in normal and type 2 diabetic patients," Diabetes, vol. 57, no. 5, pp. 1349-1354, 2008.

[19] Y. Higashi and M. Yoshizumi, "New methods of evaluate endothelial function: method for assessing endothelial function in humans using a strain-gauge plethysmography: nitric oxidedependent and -independent vasodilation," Journal of Pharmacological Sciences, vol. 93, no. 4, pp. 399-404, 2003.

[20] A. P. Fayh, M. Krause, J. Rodrigues-Krause et al., "Effects of Larginine supplementation on blood flow, oxidative stress status and exercise responses in young adults with uncomplicated type I diabetes," European Journal of Nutrition, vol. 52, no. 3, pp. 975983, 2013

[21] P. J. van Gurp, J. W. M. Lenders, and C. J. Tack, "Increased forearm blood flow in longstanding Type 1 diabetic patients without 
microvascular complications," Diabetic Medicine, vol. 24, no. 2, pp. 208-210, 2007.

[22] G. S. Berenson, S. R. Srinivasan, and T. A. Nicklas, "Atherosclerosis: a nutritional disease of childhood," American Journal of Cardiology, vol. 82, no. 10, pp. 22T-29T, 1998.

[23] T. Furumoto, N. Saito, J. Dong, T. Mikami, S. Fujii, and A. Kitabatake, "Association of cardiovascular risk factors and endothelial dysfunction in Japanese hypertensive patients: implications for early atherosclerosis," Hypertension Research, vol. 25, no. 3, pp. 475-480, 2002.

[24] G. V. Cé, L. E. Rohde, A. M. V. da Silva, M. K. Puñales, A. C. de Castro, and M. C. Bertoluci, "Endothelial dysfunction is related to poor glycemic control in adolescents with type 1 diabetes under 5 years of disease: evidence of metabolic memory," Journal of Clinical Endocrinology and Metabolism, vol. 96, no. 6, pp. 1493-1499, 2011.

[25] M. M. Duck and R. P. Hoffman, "Impaired endothelial function in healthy African-American adolescents compared with caucasians," Journal of Pediatrics, vol. 150, no. 4, pp. 400-406, 2007.

[26] T. Hortenhuber, B. Rami-Mehar, M. Satler et al., "Endothelial progenitor cells are related to glycemic control in children with type 1 diabetes mellitus over time," Diabetes Care, vol. 36, no. 6, pp. 1647-1653, 2013. 


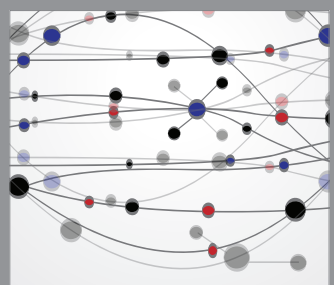

The Scientific World Journal
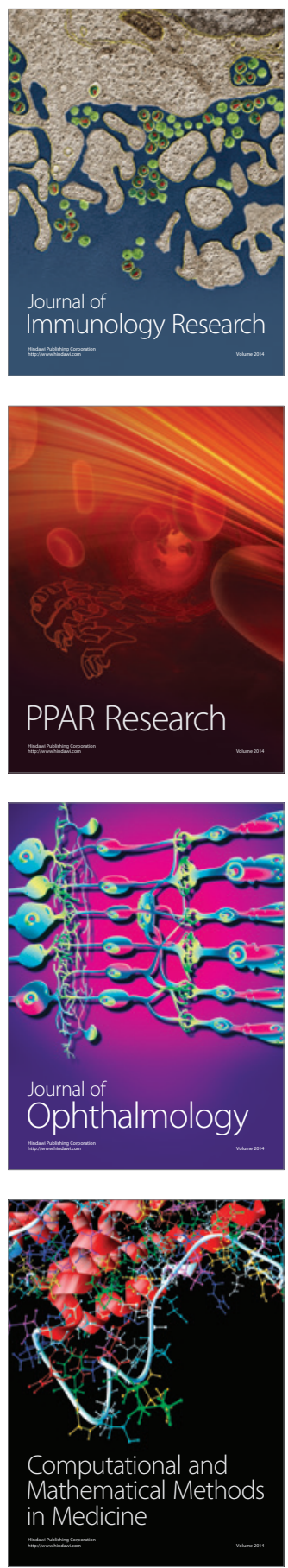

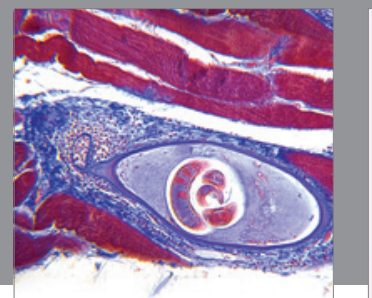

Gastroenterology

Research and Practice
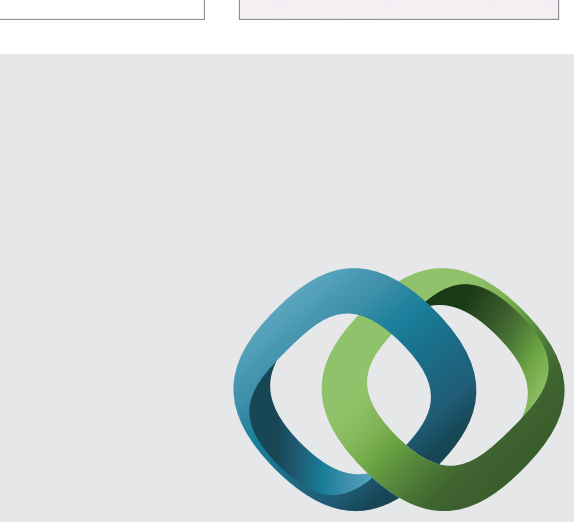

\section{Hindawi}

Submit your manuscripts at

http://www.hindawi.com
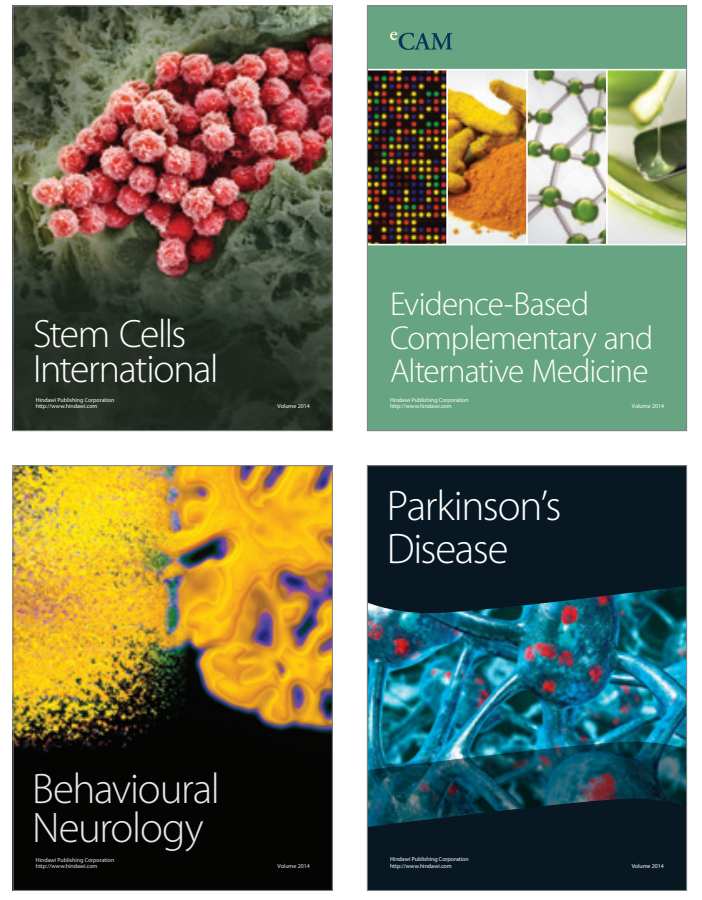
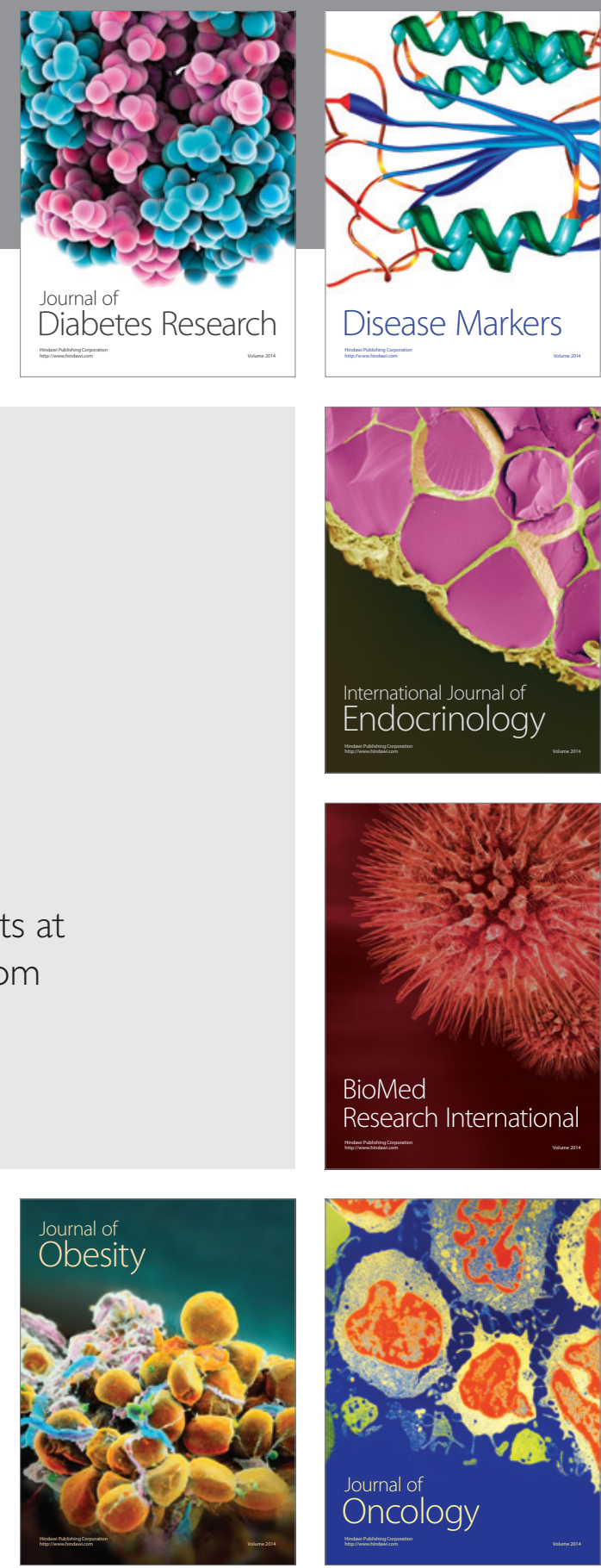

Disease Markers
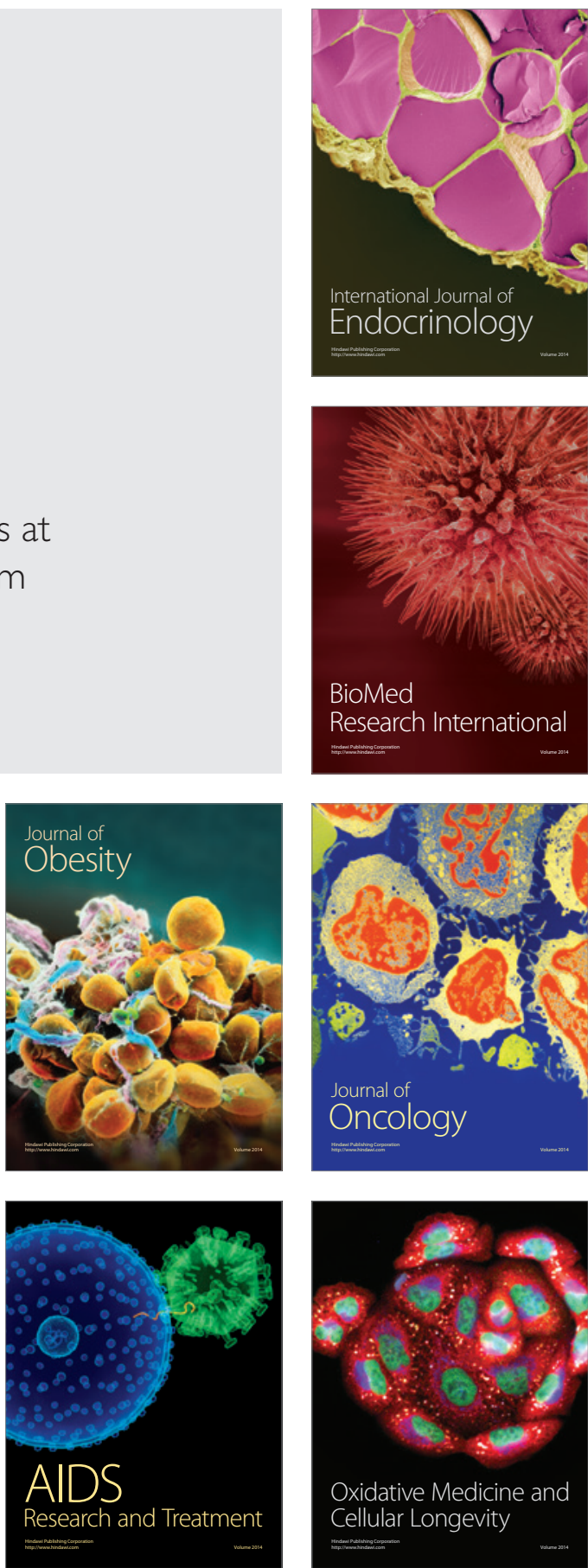